\title{
ALFABETIZAÇÃO E LETRAMENTO DE ALUNOS COM TRANSTORNO DO ESPECTRO DO AUTISMO (TEA)
}

\author{
LITERACY AND LITERACY OF STUDENTS WITH AUTISM SPECTRUM DISORDER (ASD)
}

\author{
Mayra Ferreira Barreto \\ Universidade Federal de Sergipe, Sergipe, SE, Brasil. E-mail: mayra.barreto@outlook.com
}

DOI: https://doi.org/10.46550/amormundi.v2i4.98

Recebido em: 27.06.2021

Aceito em: 24.07.2021

\begin{abstract}
Resumo: $\mathrm{O}$ presente trabalho tem o intuito de fazer uma reflexão sobre o processo de alfabetização e letramento de alunos com Transtorno do Espectro do Autismo (TEA). Para alcançar os objetivos almejados, a opção foi por uma pesquisa de caráter qualitativo e foi desenvolvida a partir da realização de revisão bibliográfica. A justificativa do trabalho surgiu das inquietaçôes que me acompanharam durante a minha jornada como professora pedagoga da sala regular, na rede pública de ensino e dos desafios que são postos para a alfabetização de alunos com autismo, tendo em vista as precariedades que a educação pública brasileira apresenta. $\mathrm{O}$ processo de alfabetização no contexto do país nos releva a necessidade de superação de práticas mecanicistas e de colocar o aluno como sujeito ativo no processo de aprendizagem. Dessa forma, a pesquisa visa contribuir para o ensino-aprendizagem da criança e adolescente autista, defendendo a articulação entre a alfabetizaçáo e o letramento com as práticas sociais do estudante.
\end{abstract}

Palavras-chave: Inclusão Escolar. Alfabetização. Letramento. Transtorno do Espectro do Autismo (TEA).

Abstract: This paper aims to reflect on the literacy and literacy process of students with Autism Spectrum Disorder (ASD). In order to achieve the desired objectives, the option was for a qualitative research and was developed based on a literature review. The justification for the work arose from the concerns that accompanied me during my journey as a pedagogical teacher in the regular classroom, in the public school system and the challenges that are posed to the literacy of students with autism, given the precariousness that Brazilian public educa-tion features. The literacy process in the context of the country reveals the need to overcome mechanistic practices and place the student as an active subject in the learning process. Thus, the research aims to contribute to the teaching-learning of autistic children and adolescents, defending the link between literacy and literacy with the student's social practices.

Keywords: School inclusion. Literacy. Literacy. Autism Spectrum Disorder (ASD).

\section{Introduçáo}

$\mathrm{O}$ presente trabalho tem o intuito de fazer uma reflexáo sobre o processo de alfabetização e letramento de alunos com Transtorno do Espectro do Autismo (TEA) na rede regular de ensino. $\mathrm{O}$ trabalho tem por objetivos: compreender os principais desafios e as possibilidades da alfabetização do aluno com (TEA), elaborar uma breve trajetória 
conceitual sobre o Transtorno do Espectro do Autismo ao longo das décadas, refletir sobre a Sala de Recursos Multifuncionais na inclusão dos alunos com TEA e apresentar estratégias de alfabetização e letramento para professores que tenham na sala, de ensino regular, alunos autistas.

Para realização dos objetivos almejados, a pesquisa utilizou os estudos de Conceição (2019), Queiroz e Ferreira (2018), Santos e Araújo (2018), Silva (2018), Brito (2017), Nascimento (2016), Guedes; Tada (2015), Capellini et al.(2013), Souza (2012) e Belizário Filho e Cunha (2010).

Os desafios encontrados para ensinar alunos com Transtorno do Espectro do Autismo (TEA) na rede regular de ensino são diversos. A maioria das escolas públicas do Brasil não está preparada para receber autistas, pois são necessários: investimentos na estrutura física dos estabelecimentos do ensino, formação inicial e continuada de professores e de profissionais da educação, de maneira que possa permitir a aprendizagem do estudante. Além da falta de capacitaçáo de professores, podemos citar também: práticas tradicionais de alfabetizaçáo (repetição e copia de palavras e frases), colocando dessa maneira o aluno como um ser passivo. Nesse contexto, é possível também notamos a falta de diagnóstico clínico precoce, emitido pelo médico, o qual dificulta a inclusão do estudante autista na escola, outra dificuldade é a ausência de diálogo da instituição de ensino com a família da criança com (TEA).

O diagnóstico emitido pelo médico é de grande importância para identificar as necessidades e especificidades da criança autista, ajudando no processo de aprendizagem dela. De acordo com Brito (2017) "o diagnóstico não pretende rotular de forma negativa ou sentenciar a pessoa, ao contrário disso, ele auxilia na comunicação entre os profissionais, na busca por direitos, ajuda a nortear as intervençóes e a orientar os familiares" (BRITO, 2017, p. 13).

Para a superação dos desafios da aprendizagem de alunos com (TEA), apresentamos algumas estratégias: adaptação do planejamento escolar e do projeto pedagógico a realidade do aluno autista, incluindo-o nas atividades apresentadas na escola e na interação com os colegas de classe. No planejamento deverá conter, sempre que necessárias adaptaçóes dos objetivos, dos conteúdos, do ambiente, dos materiais e da avaliação, permitindo, dessa forma, construir vínculo com o estudante autista. Para com isto, possibilitar um ensino sem preconceitos e com condiçóes de pleno acesso, permanência e participaçáo ativa e reflexiva da criança e do adolescente autista na escola.

É necessário que a escola acolha o aluno e seus familiares, recebendo a família na escola e tentando identificar, através de entrevista: os gostos, os medos, as potencialidades e as dificuldades dos alunos. Se o estudante não tiver acompanhamento terapêutico, a escola deverá encaminhar ou buscar parceria com órgãos municipais, estaduais e federais. De acordo com Belizário Filho e Cunha (2010):

A escola precisa estar em permanente interlocução com a família. Além de todos os benefícios inerentes a essa interlocução, isso poderá contribuir para que, juntos, a família e os profissionais da escola possam compreender mais rapidamente os motivos para eventuais retomadas pela criança de reaçôes que já haviam sido superadas (BELISÁRIO FILHO; CUNHA, 2010, p. 25).

É importante também a coordenação entre os familiares do aluno, profissionais de educação, fonoaudiólogos, psicopedagogos, pediatras, psiquiatras, neurologistas, terapeutas ocupacionais para o desenvolvimento cognitivo, afetivo e social do aluno autista. Com o 
trabalho conjunto, deste profissional é possível compreender as reais necessidades dos discentes com (TEA) e perceber como se comportam, como se sentem e percebem o que esta ao seu redor. Dessa maneira, o professor poderá adaptar a metodologia e as estratégias a necessidade do aluno auxiliando positivamente em diversas situações da sua vida estudantil.

Segundo Conceição (2019) "sem uma visão individualizada, com profissionais qualificados e métodos alternativos, estaremos negando o direito à educação dos alunos com autismo e quadros similares" (CONCEIÇÃO, 2019, p. 03). Diante do exposto, a parceria entre a escola, a família e a equipe multifuncional é de fundamental importância para o sucesso do ensino-aprendizagem do autista. De acordo com Brito (2017):

Diversos estudos científicos mostram que quanto mais precocemente à criança com TEA for encaminhada e avaliada de forma adequada, melhores poderão ser suas oportunidades de intervenção e de desenvolvimento. A intervenção precoce é fator fundamental na evolução de crianças com TEA. Este fato está diretamente relacionado à neuroplasticidade ao longo da primeira infância. Portanto, quanto mais precoce a intervenção, melhores os resultados para a criança e para sua família (KASARI et al., 2006; KELLEY et al., 2006, aput, BRITO, 2017, p. 16 ).

Deste modo, o trabalho de alfabetização com as crianças com (TEA) exigirá do professor alfabetizador novas técnicas de ensino e aprendizagem, bem como uma percepçáo de colocar o aluno como centro do ensino e como ser capaz de aprender a ler e escrever. O educador deverá buscar conhecimentos, estratégias e recursos diferenciados para tornar sua prática pedagógica mais inclusiva e ativa, pois, a alfabetização de crianças autista é uma forma de torná-la a ser autônoma e participação na vida social.

\section{Metodologia}

Para alcançar os objetivos almejados, a opção foi por uma pesquisa de caráter qualitativo e foi desenvolvida a partir da realização de revisão bibliográfica. $O$ trabalho utilizou como instrumentos de coleta de dados: o uso de livros, dissertaçóes, teses e leitura de artigos científicos publicados em repositórios acadêmicos - Coordenação de Aperfeiçoamento de Pessoal de Nível Superior (CAPES), além da seleção de normas educacionais, disponíveis no site do Ministério da Educação e do planalto do Brasil.

Dessa maneira, a pesquisa foi dividida nas seguintes fases: identificação do tema; levantamento da questão de pesquisa; escolha de estudos publicados entre 2010 a 2020 sobre "alfabetização", "letramento", "Transtorno do Espectro do Autismo (TEA)" e "inclusão escolar"; além da construção de fichamentos e produção escrita dos dados analisados. Não foi incluído no presente estudo trabalhos: repetidos, formato de resumos e que não condiziam com a temática da pesquisa. Ao longo do estudo foram analisados 30 artigos, sendo apenas 15 considerados relevantes ao objetivo proposto no trabalho.

\section{Resultados e discussáo}

Nos últimos anos temos presenciado avanços significativos nas políticas públicas na espera educacional de pessoas com deficiência. Esse fato é resultado de lutas de diversos setores da sociedade para a inclusão social e escolar de portadores de necessidades especiais. Pois, 
por muito tempo estas pessoas eram consideradas inferiores e segregadas da sociedade sendo impedidas de exercer seu papel como cidadãs e excluídas de qualquer tipo de convívio. De acordo com Souza (2012):

[...] na Idade da Pedra, algumas pessoas com deficiência física eram exterminadas. [...] $\mathrm{Na}$ Idade Média, as pessoas com deficiência passaram a ser amparadas pelos senhores feudais. No entanto, eram tratadas como doentes e vistas ora como pessoas possuídas pelo demônio, ora como seres divinos. Depois da Revoluçáo Francesa, a deficiência foi vista pela primeira vez como assunto de médico. As pessoas eram encaminhadas para instituiçóes; estudavam e trabalhavam, mas ainda sem qualquer possibilidade de serem reintegradas à sociedade. São desse período inventos como as cadeiras de rodas, as bengalas, as muletas e as primeiras próteses (SOUZA, 2012, p. 47).

Para a autora, a marginalização das pessoas com deficiência, era vista como uma descrença e incapacidade nas possibilidades de mudança de sua situação, que por muito tempo na história, era considerada anormal.

Segundo Souza (2012) "os estudos sobre as deficiências iniciaram na Europa, a partir do século XVI, como uma preocupação da medicina em classificar os indivíduos que se desviaram do padrão de normalidade definido para a época” (SOUZA, 2012, p. 87). Ainda de acordo com a autora "até o século XIX e as primeiras décadas do século XX educar o anormal era algo muito moderno e, na maioria das vezes era visto como tarefa impossível. Educar o anormal ainda era entendido como cuidar, dar assistência, atenção" (SOUZA, 2012, p. 86).

O Brasil incorporou atenção à pessoa com deficiência mental somente na primeira metade do século XX. A partir da década de 1970, começou então uma preocupação do acesso a pessoa com deficiência nas escolas, através da Educação Especial. É importante percebemos que nesse período as pessoas recebiam um atendimento de caráter educacional, mas o ensino não tinha caráter inclusivo, ou seja, era um sistema especializado que ocorria separado ao ensino regular.

Com a intenção de acabar com a segregação do ensino especializado, a Constituição Federal Brasileira (1988) no artigo no 208, inciso III estabelece o "atendimento educacional especializado aos portadores de deficiência, preferencialmente na rede regular de ensino" (BRASIL, 1988, p.69). Outro documento de fundamental importância para a consolidação dos direitos da educação inclusiva foi a Declaração de Salamanca (Espanha, 1994), este documento estabelece o comprometimento, dos países que participaram da Conferência Internacional, com a eliminação de barreiras que vinham excluindo as pessoas com deficiência física e mental do convívio social.

Seguindo na trajetória de políticas públicas para a educação inclusiva, a Lei de Diretrizes e Bases da Educação Nacional (Lei 9394/96), conhecida como a lei magna da educação escolar brasileira traz importantes conquistas para a inclusão de pessoas com deficiências. Destacaremos o seu Art. 58, que classifica a educação especial como modalidade de ensino, prever a igualdade de condiçôes de acesso e permanência na escola, além de possibilitar garantias do aluno especial como a oferta da matrícula na rede regular de ensino e serviços de apoio especializados.

Foi criada também em 2001 a Diretrizes Nacionais para Educação Especial na Educaçáo Básica. Importante destacar que essa norma apresenta o perfil do aluno com necessidades especiais, além de conceituar a Sala de Recursos. De acordo com o documento a Sala de Recursos é: 
[...] serviço de natureza pedagógica, conduzido por professor especializado, que suplementa (no caso dos superdotados) e complementa (para os demais alunos) o atendimento educacional realizado em classes comuns da rede regular de ensino. Esse serviço realiza-se em escolas, em local dotado de equipamento e recursos pedagógicos adequados às necessidades educacionais especiais dos alunos, podendo estender-se a alunos de escolas próximas, nas quais ainda não exista esse atendimento. Pode ser realizado individualmente ou em pequenos grupos, para alunos que apresentem necessidades educacionais especiais semelhantes, em horário diferente daquele em que frequentam a classe comum. (MEC, 2001, p.50).

Com o que foi exposto acima, identificamos que a partir do século XX, a educação inclusiva teve auxílio de muitos políticos, educadores, pais e instituiçóes que se identificaram com a situação de exclusão vivenciada pelas pessoas com deficiência e que contribuíram para a elaboração de normas que deram passos significativos para a construção de uma história com mais direitos, garantias e inclusão da pessoa com necessidades especiais.

\subsection{Transtorno do Espectro Autista (TEA)}

O Transtorno do Espectro Autista (TEA) passou por inúmeras alteraçóes e classificaçóes ao longo do tempo, no qual, em cada década, foram identificadas novas características específicas. As primeiras descrições do autismo foram feitas no ano de 1943, com os estudos do médico austríaco Leo Kanner. Ele afirmou que o autismo era a "incapacidade para relacionar-se normalmente com as pessoas e as situaçôes” (KANNER, 1943, p. 20 apud. BELISÁRIO FILHO; CUNHA, 2010, p. 09). Até a década de 1960, o autismo estava relacionado a um transtorno emocional, no desenvolvimento da criança, cuja causa estava vinculada a incapacidade dos pais em oferecer afeto aos filhos quando pequenos, sendo essa teoria contestada posteriormente por outros estudos.

O conceito de Transtornos Globais do Desenvolvimento, de acordo com Belizário Filho e Cunha (2010), surge no final dos anos 60 "derivado especialmente dos trabalhos de M. Rutter e D. Cohen. Ele traduz a compreensão do autismo como um transtorno do desenvolvimento, deixando assim de ser apresentado como uma psicose infantil" (BELIZÁRIO FILHO E CUNHA, 2010, p. 12). Nos dias atuais, o termo autismo é chamado de Transtorno do Espectro Autista (TEA) pelo Manual Diagnóstico e Estatístico de Transtornos Mentais (DSM-V). De acordo com o (DSM-V):

O transtorno do espectro autista é um novo transtorno que engloba o transtorno autista (autismo), o transtorno de Asperger, o transtorno desintegrativo da infância, o transtorno de Rett e o transtorno global do desenvolvimento sem outra especificação do DSM-IV. Ele é caracterizado por déficits em dois domínios centrais: 1) déficits na comunicação social e interação social e 2) padróes repetitivos e restritos de comportamento, interesses e atividades (APA, 2014, p.809 apud. SILVA; OLIVEIRA, 2018, p. 130).

De acordo com o (DSM V), pessoas com Transtornos do Espectro do Autismo apresentam as seguintes características:

A - Deficiências persistentes na comunicação e interação social: 1. Limitação na reciprocidade social e emocional; 2. Limitação nos comportamentos de comunicação não verbal utilizados para interação social; 3. Limitação em iniciar, manter e entender relacionamentos, variando de dificuldades com adaptação de 
comportamento para se ajustar as diversas situaçóes sociais.

B - Padróes restritos e repetitivos de comportamento, interesses ou atividades, manifestadas pelo menos por dois dos seguintes aspectos observados ou pela história clínica: 1. Movimentos repetitivos e estereotipados no uso de objetos ou fala; 2. Insistência nas mesmas coisas, aderência inflexível às rotinas ou padróes ritualísticos de comportamentos verbais e não verbais; 3. Interesses restritos que são anormais na intensidade e foco; 4. Hiper ou hiporreativo a estímulos sensoriais do ambiente.

C - Os sintomas devem estar presentes nas 13 primeiras etapas do desenvolvimento. Eles podem não estar totalmente manifestos até que a demanda social exceder suas capacidades ou podem ficar mascarados por algumas estratégias de aprendizado ao longo da vida.

D - Os sintomas causam prejuízo clinicamente significativo nas áreas social, ocupacional ou outras áreas importantes de funcionamento atual do paciente. E esses distúrbios não são melhores explicados por deficiência cognitiva ou atraso global do desenvolvimento (APA, 2013, apud. BRITO, 2017, p. 12 e13)

Para as autoras Guedes e Tada (2015) "as características do autismo variam na maneira como se manifestam e no grau de severidade, estando dificilmente presente da mesma maneira em mais de uma pessoa" (GUEDES e TADA, 2015, p. 303).

Não existe uma única manifestação do autismo, ele pode ser classificado em vários níveis, mas podemos de forma geral identificar alguns sintomas presente nas crianças que são: dificuldade na comunicação, gestos e emoçôes; prejuízos na interação social; comportamentos repetitivos sem uma finalidade clara; intolerância a sons e luzes; falta de contato visual e físico. Dessa maneira, também é muito comum no autista o isolamento e a falta de interesse por brincadeiras coletivas; a hiperatividade; e a agressividade, com destaque ao último que contribui muito para a exclusão do aluno autista na sala de aula, principalmente por parte dos colegas de classe. É importante ressalvar que existem crianças que são autistas e apresentam inteligência normal possuindo altas habilidades, especialmente com a matemática.

Os sinais de autismo podem ser percebidos em crianças a partir dos primeiros anos de vida. As principais características de pessoas com Transtornos do Espectro do Autismo são: repetição de fala das outras pessoas (ecolalias), dificuldade em compreender metáforas, ausência ou pouco contato visual, sensibilidade a aspectos sensoriais, como a barulho, toques e texturas, dificuldade em brincar de jogos que exige imaginação, apego por rotinas, atraso na fala, (afetando a comunicação verbal e não verbal), além de distúrbios do sono e alimentares, algumas crianças autistas podem apresentar comportamentos agressivos.

Além disso, o autismo deve ser diagnosticado precocemente para que a criança tenha bons resultados no seu tratamento além de ser acompanhado de apoio especializado, através de um sistema eficiente de comunicação em que participem profissionais de psicologia, fonoaudiologia, fisioterapia, psicopedagogo, terapeuta ocupacional além de psiquiatras e neuropsiquiatrias familiarizados com o TEA.

Crianças com autismo podem desenvolver conhecimentos específicos em determinadas áreas do conhecimento, desde que essas capacidades sejam estimuladas, para isto, a escola tem um papel importante de contribuir no desenvolvimento do aluno.

Outra norma importante é a lei 12.764/2012 que faz referência ao Transtorno do Espectro 
Autista, essa lei traz várias garantias ao autista dentre elas estão: o reconhecimento do autismo como uma deficiência intelectual e que requer necessidades especiais; reconhece o diagnóstico precoce, o tratamento multidisciplinar e a matrícula em rede regular de ensino da educação infantil até o ensino médio, sob multa à instituição que descumprir a legislação. A norma ainda estabelece o acesso:

a) à educação e ao ensino profissionalizante; b) à moradia, inclusive à residência protegida; c) ao mercado de trabalho; d) à previdência social e à assistência social Porém, nem todas as escolas ainda dispóem de recursos tanto materiais, quanto humanos, suficientes para isso (BRASIL, 2012, p. 02).

A legislação traz diversas garantias para o autista, mas nem sempre é aplicada de forma eficaz. Ainda faltam escolas que ofereçam atendimento especializado, recursos materiais e humanos entre outros fatores que serão abordados ao longo desse trabalho.

Já no processo de alfabetização e letramento, a criança com (TEA) costuma a apresentar falta de curiosidade pela leitura e pela escrita, falta de comunicação e de socialização, além de grafismo rudimentar. De acordo com Belizário Filho e Cunha (2010) é possível também identificar movimentos corporais estereotipados em pessoas autistas que envolvem:

[...] mãos (bater palmas, estalar os dedos), ou todo o corpo (balançar-se, inclinarse abruptamente ou oscilar o corpo), além de anormalidades de postura (ex.: caminhar na ponta dos pés, movimentos estranhos das mãos e posturas corporais). Podem apresentar preocupação persistente com partes de objetos (botóes, partes do corpo). Também pode haver fascinação por movimentos (rodinhas dos brinquedos, abrir e fechar portas, ventiladores ou outros objetos com movimento giratório) (BELISÁRIO FILHO; CUNHA, 2010, p. 15).

Dito isto, a classificação do Transtorno do Espectro Autista (TEA) pelo Manual Diagnóstico e Estatístico de Transtornos Mentais (DSM-V), datado do ano de 2013, foi um avanço muito importante para a inclusão das pessoas com autismo, pois possibilitou o acesso a novas oportunidades, recursos e políticas públicas. De acordo com Queiroz e Ferreira (2018) é importante também que haja "um grande esforço de conscientização do público quanto ao uso das categorias diagnósticas como instrumentos de ação dos profissionais e não para o julgamento das pessoas pela sociedade" (QUEIROZ; FERREIRA, 2018, p. 04).

\subsection{Sala de recursos multifuncionais e a inclusão dos alunos com TEA}

Conforme o Decreto n 7.611/2011, Art. 5, § 30 "as salas de recursos multifuncionais são ambientes dotados de equipamentos, mobiliários e materiais didáticos e pedagógicos para a oferta do atendimento educacional especializado" (BRASIL, 2011, p. 02). Nas salas multifuncionais são oferecidas o Atendimento Educacional Especializado (AEE), que deve ser realizado na escola em que o aluno estuda, ou, caso desta não disponibilizar esse serviço, em outra instituição que se localize o mais próximo possível de sua residência, sempre no turno inverso ao da escolarização regular.

A (SRM) tem como função identificar, elaborar e organizar recursos pedagógicos e de oferecer acessibilidade e a participação dos alunos, considerando suas necessidades específicas. As atividades desenvolvidas no atendimento educacional especializado diferenciam-se daquelas realizadas na sala de aula comum, pois, seu principal objetivo é assegurar o pleno acesso do sujeito com deficiência, transtornos globais do desenvolvimento ou altas habilidades/superdotação no 
ensino regular em igualdade de condiçóes dos demais alunos.

O aluno que necessitar de AEE tem direito a duas matrículas: uma em classe comum da rede pública de ensino e outra no atendimento educacional especializado. $\mathrm{Na}$ sala de recursos o professor desenvolve os processos cognitivos e a psicomotricidade dos alunos, além de estimular a autoestima do educando para que este tenha sucesso na sala regular de ensino. As atividades elaboradas na (SRM) envolve jogos, atividades lúdicas que desenvolvam a concentração dos alunos e o seu raciocínio.

As atribuiçôes do professor que atua nas (SRM) são as seguintes: identificar as necessidades educacionais especifica dos alunos, elaborar um planejamento individualizado, garantir o desenvolvimento do aluno, a sua permanência na escola e a participação nas atividades da classe comum. As atividades desenvolvidas na (SRM) deve caminhar junto ao projeto da sala de aula regular, o educador da sala de recursos deve informar aos professores da sala comum, quais as melhores metodologias que se deve trabalhar.

Para que a mediação educativa aconteça é preciso que o educador conheça os aspectos do transtorno, assim como os métodos e programas desenvolvidos para auxiliá-lo na educação da criança autista. O professor da (SRM) não trabalha com conteúdos de português, matemática, ciências, mas com os princípios cognitivos que vão levar a aprendizagem dessas disciplinas.

É de fundamental importância à interação do profissional das salas de recursos com a família do educando autista, pois, contribui para a sua aprendizagem. A escola e a família devem ser parceiras no que diz respeito ao desenvolvimento do educando e manter o constante diálogo. A família deve esta ciente da necessidade do seu filho, em levá-lo para a sala de recursos, informar do que o aluno gosta, qual a sua potencialidade e dificuldade. Todas essas informaçóes são essenciais para facilitar o trabalho do professor.

As (SRM) são uma grande conquista para a educação especial, mas ainda a inclusão de alunos com autismo é um grande desafio, pois muitos professores da sala de aula regular não tem formaçáo inicial e continuada para ensinar alunos com necessidades educacionais especiais. Diante desta realidade, é fundamental que o professor da classe comum seja orientado na busca de novas práticas educativas, a atuar em conjunto com professores das diferentes disciplinas na escolarização.

$\mathrm{Na}$ grande maioria dos casos quem acompanha o aluno é alguém que não tem formação adequada e capacitação com alunos autista. Fora os casos em que o aluno simplesmente não tem nenhum acompanhante. As instituiçóes de ensino públicas precisam ter estruturas físicas e recursos para o acolhimento do aluno especial. É importante também a participação da comunidade escolar e à sociedade em geral o papel de incentivar e fiscalizar medidas comprometidas com a inclusão de pessoas com deficiência. Devemos também quebrar a barreira na crença que o aluno com necessidades especiais não tem condiçóes de aprender. Dessa forma, a escola deve se estruturar para oferecer a aprendizagem desses alunos através de um currículo flexível, rede de apoio, sala de recursos, avaliaçóes diferenciadas e principalmente acreditar no potencial do aluno com necessidades especiais. 


\subsection{Estratégias para trabalhar com o aluno autista no ambiente escolar}

A seguir vamos apresentar algumas metodologias que poderão ser utilizadas pelos professores para a alfabetização e letramento de criança autista. As estratégias aqui sugeridas devem ser aplicadas levando-se em contas as características da criança, os seus interesses, e as suas especificidades. Também é de fundamental importância à participação dos pais ou responsável para o sucesso da aprendizagem do estudante autista. De acordo com Santos e Araújo (2018):

[...] o processo de alfabetização é algo complexo e que deve ser contextualizado e problematizado juntamente com as crianças, partindo da realidade em que o aluno está inserido, ou seja, o de leitura do mundo no qual os autores denominam de letramento, já o processo de decodificação de sons e sílabas, muitos autores defendem como alfabetização, em sentido restrito (SANTOS; ARAÚJO, 2018, p. 02).

A alfabetização é um processo importante na vida de toda criança, principalmente do aluno autista, pois permite que ele interaja com o mundo, compreenda a sua realidade e tenha um papel de ação diante das todas as barreiras que lhe são impostas. O processo de alfabetização não é somente a união de letras, sem levar a reflexão o que escrito, é necessário que o professor contextualize a realidade do aluno a partir do que se está lendo. De acordo com Nascimento (2016):

(...) para a alfabetização de alunos autistas deixar de ser utopia ou casos isolados de apropriação da Língua Portuguesa, são necessários que alguns pilares fundamentais sejam apropriados pelos professores, como: a transformação da atitude docente em professor-pesquisador para o ensino de alunos autistas; a compreensão de que a prática pedagógica precisa ser organizada por método de ensino; a definição e utilizaçâo de materiais didáticos acessíveis para alunos autistas; adquirir, além dos conhecimentos básicos referentes aos conteúdos pedagógicos a serem ensinados, conhecimentos de Psicologia Comportamental e funcionamento cerebral. (NASCIMENTO, 2016, p. 65).

Para que a inclusão do estudante ocorra, o processo de alfabetização deve está vinculada ao letramento e com a utilização de estratégias de ensino bem diversificadas, requerendo do professor uma postura política, reflexiva e inovadora, por isso, a importância da qualificação continuada.

$\mathrm{O}$ aluno com (TEA) precisa de um ensino direcionado que o oriente a expressar seu pensamento e sua emancipação. As atividades devem está voltadas para a ludicidade e interação para que o ensino não se torne "cansativo", "chato" e "decoreba". As metodologias apresentadas, pelo professor, em sala de aula devem estimular a criatividade e a participação do aluno autista. A seguir serão apresentadas algumas estratégias, seguindo as orientaçóes de Brito (2017), Conceição (2019), Belizário Filho e Cunha (2010), e Silva (2018) que poderão ser utilizadas pelo professor na sala de aula.

A literatura é uma grande aliada para a alfabetização e a inclusão do aluno autista. Ela contribui para práticas alfabetizadoras despertando no aluno a imaginação. $\mathrm{O}$ texto literário associado ao uso de imagens promove um aprendizado rico de significado, possibilitando o aluno expressar seus sentimentos e emoções. Uma boa dica é a utilização da literatura infantil e a produção de textos, através de desenhos. Para Silva (2018), o trabalho com o livro de literatura infantil é um "instrumento rico não só da língua escrita, mas de outras linguagens, como a 
visual, para apoiar o processo de alfabetizaçáo" (SILVA, 2018, p. 08).

Os processos de alfabetização em crianças autistas devem ser específicos em razão da individualidade de cada aluno. É importante também que os pais e familiares, estimulem a leitura em casa. Para o processo de letramento, o docente poderá utilizar animais ou personagem favoritos da criança para despertar o interesse pela tarefa. Segundo Queiroz e Ferreira (2018), o professor deve observar, quando selecionar uma atividade "que seja mais lúdica, que se torne mais prazerosa e que não demandem tanto tempo, que não sejam tão longas e que atraiam a atenção dele, coisas que ele se sinta atraído” (QUEIROZ; FERREIRA, 2018, p.21).

Em criança com pouca coordenação motora o professor poderá realizar atividades que desenvolva a coordenação, através de tarefas em que a criança possa amassar papel, recortar, pegar pequenos objetos, essas estratégias poderão ajudar a produção da escrita. Em relaçáo ao material didático utilizado pelo aluno autista, o professor, de acordo com Nascimento (2016) deverá "combinar cores que estimulam a memorização e a atividade cerebral, combinado como materiais didáticos adequados para a memorização visual e auditiva" (NASCIMENTO, 2016, p. 74). O material deverá ser fácil manipulação e resistente ao uso no dia a dia e, se possível, confeccionado em tons vermelhos ou alaranjados para estimular a concentração e a memorização do aluno com (TEA). Para facilitar a comunicação entre o aluno, o professor e os colegas da classe o ideal é que o professor utilize frases curtas e objetivas.

Para permitir o desenvolvimento cognitivo do aluno, o educador poderá: estimular o interesse por brinquedos ensinando-lhe a brincar de forma adequada e sempre explicando o que está fazendo e o que vai fazer. Estimular jogos que use a imaginação da criança, explicando que ela pode ganhar ou perder o jogo.

Faz necessário que o docente receba atentamente as respostas do aluno com paciência quando lhe fizer uma pergunta ou proponha uma atividade. Sempre procurando elogiar a criança quando ela atender as suas solicitaçôes, promovendo assim a interação social. De acordo com Brito (2017):

O uso de recursos visuais também é sistematicamente destacado quando o assunto é intervenção nos TEA. A utilização de recursos visuais como desenhos, figuras, fotografias, vídeos ou objetos concretos associados ao aspecto que se pretende desenvolver ou à atividade planejada, pode ajudar na compreensão e interesse de crianças e adultos com TEA. Usar quadros de rotina diária em casa, na terapia e na escola, passo a passo de algumas situaçóes do cotidiano, por exemplo, de como usar o banheiro ou tomar banho. Usar histórias sociais para situaçôes sociais do cotidiano, como cumprimentar as pessoas, esperar sua vez para falar, despedirse, etc. $\mathrm{O}$ uso de recursos de tecnologia com computadores, tablets, celulares, aplicativos, kits de robótica e robôs humanoides despertam o interesse de muitas crianças com TEA. Habilidades comunicativas, sociais e acadêmicas podem ser promovidas com o auxílio destes e de outros recursos tecnológicos. A leitura de histórias pode ser também bastante incentivadora para alguns. O tipo de material e como conduzir a situação dependerá dos interesses e habilidades da criança. Por exemplo, começar livros que contenham muitas imagens grandes e coloridas e histórias curtas (BRITO, 2017, p. 22 e 23)

É importante utilizar atividades que desenvolva o psicomotor e o sensorial da criança a exemplo de texturas diferentes, elementos da natureza água, areia, etc. Promova situaçóes que incentivem a convivência com outras crianças ou pessoas da mesma faixa etária. Evite o 
excesso de sons misturados, televisão e a circulação excessiva de pessoas. Essas foram algumas estratégias que poderão ser utilizadas na sala de aula para facilitar o processo de alfabetizaçáo e letramento de crianças autista. Entretanto, são muitos os obstáculos que precisam ser superados para a inclusão de alunos com autismos nas escolas públicas do Brasil. Sabemos que, apesar das diversas conquistas, a inclusão de alunos com deficiência ainda está longe do ideal. No entanto, é possível que a escola, mesmo com pouco recurso e tempo, contribua para o processo de ensinoaprendizagem do aluno com (TEA).

\section{Consideraçóes finais}

Neste trabalho, dedicamo-nos a estudar sobre o processo de alfabetização e letramento de alunos com Transtorno do Espectro do Autismo/TEA. A pesquisa conseguiu atingir os objetivos propostos, na medida em que mostrou a possibilidade da alfabetização do aluno com autismo e da sua inclusão na classe comum, sendo necessário que a escola e a família acreditem no potencial do aluno. Dessa forma, o professor também deverá está sempre buscando através de práticas pedagógicas alternativas diferenciadas que possibilite a aprendizagem do aluno autista, oferecendo novas oportunidades, a partir de uma educação de qualidade e ação inclusiva, exigindo, para isso, o trabalho compartilhado de todos os envolvidos com a educação.

Podemos perceber ainda, que nos últimos anos temos presenciado avanços significativos nas políticas públicas na espera educacional de pessoas com deficiência. Várias normas foram elaboradas para a inclusão dessas pessoas na sociedade a exemplo: da Constituição Federal Brasileira (1988), Declaração de Salamanca (Espanha, 1994), Diretrizes Nacionais para Educação Especial na Educação Básica (2001), Lei de Diretrizes e Bases da Educação Nacional (Lei 9394/96), a lei 12.764/2012 e o Decreto no 7.611/2011. Essas legislaçóes trouxeram diversas garantias e direitos para o autista, umas delas foi o atendimento especializado que é feito através das salas de recursos multifuncionais. A (SRM) tem como objetivo principal a inclusão de alunos com (TEA) e se constitui em fundamental alicerce para a aprendizagem dos conteúdos escolares e não escolares dentro de das possibilidades individuais de cada aluno especial. Apesar das diversas garantias legais alcançadas para o autista nem sempre a lei é aplicada de forma eficaz, pois ainda faltam escolas que garantam: atendimento educacional especializado, recursos materiais e humanos, entre outros fatores que foram abordados ao longo desse trabalho.

\section{Referências}

BRASIL. Constituição da República Federativa do Brasil de 1988. Disponível em: <http://www. planalto.gov.br/ccivil_03/Constituicao/Constituicao.htm> Acesso em 25 de junho de 2020.

BRASIL. Lei de Diretrizes e Bases da Educação Nacional. Lei 9.394/96. Disponível em: <http:// www.planalto.gov.br/ccivil_03/leis/L9394.htm> Acesso em 25 de junho de 2020.

BRASIL. Ministério da Educação. Diretrizes nacionais para a educação especial na educação básical Secretaria de Educação Especial MEC/SEESP, 2001. Disponível em: <http://portal. mec.gov.br/seesp/arquivos/pdf/diretrizes.pdf> Acesso em 20 de agosto de 2020.

BRASIL. Lei n. 12.764, de 27 de dezembro de 2012. Institui a Política Nacional de Proteção dos Direitos da Pessoa com Transtorno do Espectro Autista; e altera o $\$ 3^{\circ}$ do art. 98 da Lei ${ }^{\circ}$ 
8.112, de 11 de dezembro de 1990. Disponível em:<http://www.planalto.gov.br/ccivil_03/_ ato2011-2014/2012/lei/112764.htm > Acesso em 20 de agosto de 2020.

BRASIL. Decreto no 7.611/2011. Dispóe sobre a educação especial, o atendimento educacional especializado e dá outras providências. Disponível em:<http://www.planalto.gov.br/ccivil_03/_ Ato2011-2014/2011/Decreto/D7611.htm> Acesso em 20 de agosto de 2020.

BELISÁRIO FILHO, José Ferreira; CUNHA, Patrícia. A Educação Especial na Perspectiva da Inclusão Escolar: transtornos globais do desenvolvimento. Brasília: Ministério da Educação, Secretaria de Educação Especial. Universidade Federal do Ceará, 2010.

BRITO, Maria Claudia. Estratégias práticas de intervenção nos transtornos do espectro do autismo. E-book: SaberAutismo, 2017. Disponível em: <http://www.mariaclaudiabrito.com.br/> Acesso dia 12 jan.2021.

CAPELLINI, V. L. M. F.; SHIBUKAWA, P. H.; RINALDO, S. C. O. Práticas pedagógicas colaborativas na alfabetização do aluno com Transtorno do Espectro Autista. Disponível em:<https://educere.bruc.com.br/CD2013/pdf/10470_6215.pdf> Acesso dia 12 jan. 2021.

CONCEIÇÃO, Fábio Coelho. Estratégias para uma verdadeira inclusão escolar: capacitando $o$ (a) mediador (a) escolar. Rio Grande do Sul, 2019. Disponível em: <https://www. academiadoautismo.com.br/> Acesso dia 16 jan. 2021.

GUEDES, N. P. S; TADA, I. N. C. A Produção Científica Brasileira sobre Autismo na Psicologia e na Educação. Revista Psicologia: Teoria e Pesquisa. Brasília, v.31, n.3, p. 303-309, jul.-set. 2015.

NASCIMENTO, Gisele Soares Rodrigues do. Método de Alfabetização para Alunos Autistas (MAPA): Alternativa da Clínica- Escola do Autista, 2016, p. 122. Dissertação (Mestrado Profissional em Diversidade e Inclusão) - Universidade Federal Fluminense, Niterói, 2016.

QUEIROZ, S. M. A.; FERREIRA, S. P. A. Mediação docente na alfabetização do aluno com TEA: um olhar sobre as estratégias pedagógicas na produção de texto escrito. Disponível em < https://www.ufpe.br/documents/39399/2442885/QUEIROZ_+FERREIRA+-+2018.2.pdf/ f636d050-288c-428c-b0c3-be58432fe5b5> Acesso dia 14 jan. 2021.

SANTOS, A. T. S. S.; ARAÚJO, D. K. P. de; COSTA, M. V. G. Possibilidades e desafios da alfabetizaçâo: relato de experiência de uma docente dos anos iniciais do ensino fundamental. Disponível em <https://www.editorarealize.com.br/editora/anais/cintedi/2018/TRABALHO_ EV110_MD1_SA16_ID1930_25072018101317.pdf> Acesso dia 14 jan.2021.

SILVA, Andrialex William. Metodologias para o ensino de alunos com autismo: As contribuiçóes da literatura para a alfabetização do aluno com Deficiência Intelectual, 2018. Disponível em <https:/www.editorarealize.com.br/editora/anais/cintedi/2018/TRABALHO_EV110_MD1_ SA16_ID1567_02082018184541.pdf> Acesso dia 14 jan.2021.

SILVA, Jaqueline Renata da; OLIVEIRA, Nathalia de. Crianças autistas no processo de alfabetização: práticas pedagógicas inclusivas. Revista Contemporânea: Revista Unitoledo: Arquitetura, Comunicaçâo, Design e Educação, v. 03, n. 01, p. 125- 140 jan/jun. 2018.

SOUZA, Rita de Cácia Santos. Educação especial em Sergipe do século XIX ao início do século XX: cuidar e educar para civilizar. São Cristóvão: Editora UFS, 2012. 